
\title{
$\angle$ Research Square \\ Sociodemographic disparity in health-related behaviors and dietary habits among governmental employees in Hunan, China
}

Ling Li

Central South University Xiangya School of Public Health

Jun $\mathrm{He}$

Central South University Xiangya School of Public Health

Feiyun OuYang

Central South University Xiangya School of Public Health

Dan Qiu

Central South University Xiangya School of Public Health

Yilu Li

Central South University Xiangya School of Public Health

Dan Luo

Central South University Xiangya School of Public Health

Yu Yu

Xiangya Hospital Central South University

Shuiyuan Xiao ( $\nabla$ shuiyuanxiao1503@163.com )

Central South University Xiangya School of Public Health https://orcid.org/0000-0002-7770-3797

\section{Research}

Keywords: Sociodemographic disparity, Health-related behaviors, dietary habits, Governmental employees, China

Posted Date: July 27th, 2020

DOI: https://doi.org/10.21203/rs.3.rs-44117/v1

License: (c) (i) This work is licensed under a Creative Commons Attribution 4.0 International License.

Read Full License 


\section{Abstract}

\section{Background}

Health-related behaviors and dietary habits have played essential roles in shaping population health and are related to morbidity or mortality. We aimed to estimate the distribution of health-related behaviors and dietary habits by socio-demographics among governmental employees in China.

Method

A total of 5029 participants were included in this study. Information on their sociodemographic characteristics, health-related behaviors and dietary habits was collected. Socioeconomic status (SES) scores were calculated by multiplying ordinal numerical values assigned to consecutive categories of education level and annual household income. Adjusted multinomial logistic regression analysis and categorical principal component analysis were used to estimate differences in health-related behaviors and dietary habits by socio-demographics.

Results

The distribution of health-related behaviors and dietary habits varied by sociodemographic groups. Middle-aged males (41-60 years) were more likely to smoke, use alcohol and have short sleep duration. Young participants ( $\leq 30$ years) were more likely to have multiple unhealthy behaviors and dietary habits. Those in high-SES have a lower level of smoking and leisure-time physical inactivity, but a high level of late sleeping than those in low-SES. Notably, older males ( $\geq 51 \mathrm{y}$ ) with low-SES preferred the 'smoked and pickled foods, and dessert' and 'fish and nut' pattern. In high-SES groups, 41-50 y people preferred the 'traditional foods' and 'cereals and dairy product' pattern. No difference in dietary patterns by sociodemographics were found among females.

\section{Conclusions}

Our findings of the disparity distribution of health-related behaviors and dietary habits by specific-gender, age and SES among Chinses governmental employees have important policy implications for developing targeted health interventions to facilitate health-related behaviors and dietary habits in this population.

\section{Background}

Globally, health-related behaviors and dietary habits play an essential role in shaping population health. Health-related behaviors can be defined as voluntary behaviors that related to health or disease [1], some of which may lead to negative outcomes from a health perspective, such as smoking, alcohol drinking, physical inactivity and sedentary lifestyle. Health-related behaviors have been recognized as major determinants of morbidity and mortality [2, 3], and their role extends to the development and progression of diseases, the effectiveness of treatments and quality of life[4]. The most common diseases can be prevented with the adoption of healthier behaviors $[5,6]$. Among various health-related behaviors, smoking 
is a chief contributor to morbidity and the leading cause of mortality [6, 7]. Dietary habits are the habitual decisions of individuals or group of people regarding what foods they eat[8]. Some unhealthy dietary habits (e.g., eating midnight snack and consuming pickled foods) have been shown to be associated with a higher risk of cancer[9-11]. The importance of healthy behaviors and dietary habits is underscored by the US Affordable Health Care Act, which provides unprecedented universal coverage for preventive behavioral and dietary health services[12].

The distributions of health-related behaviors and dietary habits usually differ by sociodemographic characteristics, such as gender, age and social class,[13-15]. Men (including male adolescents), for instance, are more likely than women to smoke, binge drink[16, 17]; women (including female adolescents), by contrast, are less likely to engage in physical activity[18]. Younger people were more likely to get involved in risk behaviors and unhealthy dietary habits than older people[19,20]. Those with high socioeconomic status (SES) were less likely to smoke, and have a low level of physically inactivity, but more likely to have high nutritional eating patterns [21-25]. These sociodemographic factors shape social context and day-to-day routines, which in turn influence health behaviors and dietary habits, as well as people's ability to change. Knowledge of sociodemographic-specific behavioral characteristics and their interrelationships can help pinpoint intervention targets and guide for development of efficacious interventions.

Although health-related behaviors and dietary habits have been found to be associated with sociodemographics such as gender, age and SES, these factors are usually studied separately. There is a lack of comprehensive study on health-related behaviors and dietary habits by taking account of all sociodemographic factors together, for instance, by combining age and gender. Also, most of the study were conducted in developed countries, it is also important to learn about the situation in developing countries such as China. The current study was conducted to understand the distribution of health-related behaviors and dietary habits by socio-demographics among governmental employees in urban area of China.

\section{Methods}

\section{Study design and participants}

This retrospective study was conducted between January 2018 and December 2018 in Changsha city, Hunan province of China. Briefly, a multistage sampling design was carried out to obtain a representative sample. Firstly, 10 institutions were randomly sampled from the government-run institutions that volunteered to participate in the study in Changsha city. Secondly, in each sampled institution, all the staff were selected to take part in our study using cluster sampling. In China, governmental employees are the workers in the national legislative branch, judicial branch, administrative organs, the Party organs of the Communist Party of China and the democratic parties, people's organizations and public institutions, who perform public duties according to law, such as civil servants, regular employee at university or hospital, etc. After obtaining informed consent, eligible participants were asked to complete 
a digital self-reported questionnaire. The eligibility criteria for participants included: (1) being able to speak and understand Chinese, (2) being 18-60 years old, (3) working at the selected institution, and (4) having no serious limb diseases. Finally, a total of 5029 governmental employees were include in this study.

\section{Sociodemographic characteristics}

The collected sociodemographic data included information on demographic (age, gender, marital status) and socioeconomic characteristics (education and annual household income). SES scores were calculated by multiplying ordinal numerical values assigned to consecutive categories of education level and annual household income[26]. Educational attainment was divided into six groups, and annual household income was divided into seven groups. The SES score ranged from 1 to 42 . According to the tertile values of the SES score distribution, study participants were further divided into three groups: low SES (L-SES, 1-12 points), medium SES (M-SES, 13-18 points), and high SES (H-SES, 19-42 points).

\section{Health-related behaviors}

Data on health-related behaviors was collected using standardized questionnaires, which included smoking, alcohol drinking, leisure-time physical inactivity, sedentary behavior, late sleeping, and short sleep duration. Smoking was defined as smoking at least one cigarette a day for more than half a year, which can be further classified into three status: never, former, or current smoking. Alcohol drinking was defined as dinking at least once a week for more than half a year, and can be further classified into three status: never, former, or current smoking. Leisure-time physical inactivity was defined as $30 \mathrm{~min} /$ day of physical activity at a frequency of once per week or less. Sedentary behavior was defined as more than 2 hours/day sitting (such as watching TV, surfing the Internet, etc.) apart from work and study. Late sleeping was defined as sleeping after midnight, and short sleep duration was defined as sleeping time less than 7 hours per night.

\section{Dietary habits}

Dietary habits included four eating behavior habits and 15 kinds of food consumption. Eating behavior habits included irregularly meals habit (yes or no), eating midnight snack habit (yes or no), eating gluttony habit (yes or no), and salty taste habit (yes or no). Food consumption was assessed by asking whether consuming each of the following food groups for more than 3 times/week: (i) rice; (ii) wheat; (iii) grains; (iv) fish; (v) vegetables; (vi) poultry meat; (vii) livestock meat (pork, beef/lamb); (viii) Soybean and products; (ix) fruits; (x) eggs; (xi) dairy products; (xii) nuts, (xiii) desserts $\mathbb{Z}(\mathrm{xiv})$ pickle food, and (xv) smoked fish or meat.

\section{Data Analysis}

Crude frequencies and weighted percentages were calculated for distribution of socio-demographic characteristics. Among these socio-demographic variables, gender, age and SES were considered as important factors for health-related behaviors and dietary habits. Thus, analyses of health-related 
behaviors and dietary habits were stratified by these three variables. Participants were grouped into 8 categories based on gender (male/female) and four age subgroups ( $\leq 30,31-40,41-50$ and $\geq 51$ ), and 3 categories based on SES. Weighted percentage of the six health-related behaviors and four eating habits were calculated by these categories. Adjusted multinomial logistic regression analysis was used to determine frequencies (health-related behaviors and eating habits) in L-SES and H-SES.

Categorical principal components analysis (CATPCA) was used to examine the different consumption patterns for the 15 food groups mentioned previously (Table 1, see line 541). The analysis allowed for simultaneous evaluation of the relationships between various variables. The analysis was considered reliable for Cronbach's alpha coefficient $>0.7$. All the statistical analyses were performed using SPSS version 19.0 software. A two-sided $p$-value $<.05$ was considered as being of statistical significance.

\section{Results}

\section{Sample characteristics}

A total of 5029 participants were included in the study (3006 for female; 2023 for males), and their characteristics were shown in Table 2 (see line 543). The age distribution of the sample was as follows: $19.6 \%$ of participants were $\leq 30$ years, $40.1 \%$ were $31-40$ years, $24.8 \%$ were $41-50$ years, and $15.6 \%$ were $\geq 51$ years old. Most participants were married/cohabited (84.8\%), with an education level of undergraduate/college or above (94.6\%), and with a family income level of 110,000-200,000 (36.2\%). According to the definition of SES for the current study, 35.3\% were in L-SES group, $36.6 \%$ were in M-SES group, and $28.1 \%$ were in H-SES group. The prevalence of current smoking, current alcohol drinking, leisure-time physical inactivity, sedentary behavior, late sleeping and short sleep duration among the participants was $12.0 \%, 6.7 \%, 54.8 \%, 74.8 \%, 16.6 \%$ and $34.4 \%$, respectively. Additionally, the prevalence of four eating behavior habits was $38.3 \%$ for irregular meals habit, $26.1 \%$ for salty taste habit, $4.8 \%$ for eating gluttony and $2.0 \%$ for eating midnight snack, respectively (Table 2 , see line 543 ).

\section{Distribution of health-related behaviors and eating behavior habits by gender and age}

We further examined distribution of health-related behaviors and eating behavior habits by age for men and women separately (Table 3 , see line 574). Smoking and alcohol drinking behaviors were observed for males, but hardly for females. For males, the age of $\geq 51$ years group had the highest rate of current smoking (36.2\%), current alcohol drinking (25.7\%) and short sleep duration (39.0\%). Younger males (age $\leq 40 \mathrm{y}$ ) had a high rate of leisure-time physical inactivity (age $\leq 30 \mathrm{y}: 52.8 \%$; age $31-40 \mathrm{y}: 59.6 \%$ ). The youngest age group (age $\leq 30 \mathrm{y}$ ) had the highest rate of sedentary behavior $(80.4 \%)$ and late sleeping (30.1\%). As for eating behavior habits, the youngest age group (age $\leq 30 \mathrm{y}$ ) had the highest rate of irregular meals habit (50.4\%), eating midnight snack habit (3.5\%), eating gluttony habit $(10.3 \%)$ and salty taste habit (35.8\%).

For females, the youngest age group (age $\leq 30 \mathrm{y}$ ) had the highest rate of sedentary behavior $(81.7 \%)$, leisure-time physical inactivity (69.4\%) and late sleeping (20.7\%). The $\geq 51$ age group had the highest 
rate of short sleep duration (45.4\%). As for eating behavior habits, the youngest age group (age $\leq 30 \mathrm{y}$ ) had the highest rate of irregular meals habit (61.1\%), eating midnight snack habit (3.9\%), eating gluttony habit $(7.0 \%)$ and salty taste habit $(25.6 \%)$. A negative dose-response trend increasing age was found in irregular meals habit, eating midnight snack habit and salty taste habit

\section{Distribution of health-related behaviors and eating behavior habits by SES}

Table 4 (see line 592) presented the distribution of health-related behaviors and eating behavior habits among different SES groups after adjusting for age, gender and marital status. For health-related behaviors, compared to the L-SES group, the H-SES group had lower rate of current smoking $(11.4 \% \mathrm{vs}$ $13.7 \%, p=0.006)$ and leisure-time physical inactivity ( $51.9 \%$ vs $54.4 \%, p=0.028)$, but higher rate of late sleeping (18.5\% vs $15.2 \%, p<0.001)$. No significant differences were found in the rate of current alcohol drinking, sedentary behavior and short sleep duration. Additionally, the rates of the four dietary behaviors were similar in the three different SES groups.

\section{Food consumption patterns by gender, age and SES}

CATCPA was performed to identify the patterns of food consumption for 15 food groups by gender, age and SES (Figure 1). The Cronbach's alpha was 0.887 and the total eigenvalue was 5.812 , indicating good reliability for assessment of simultaneous relationships among the selected variables. Among the 15 food groups, rice consumption habit was located in the centroid. Four food consumption patterns were identified. Pattern 1 named 'traditional foods' pattern was characterized by more consumption of vegetables, livestock and poultry meat, fruits and eggs. Pattern 2 named 'cereals and dairy product' pattern was characterized by more consumption of grain, wheat, soybean and products, and dairy product. Pattern 3 named 'fish and nut' pattern was characterized by more consumption of fish and nut. Pattern 4 named 'smoked and pickled foods, and dessert' pattern was characterized by more consumption of smoked fish or meat, pickle food and dessert. CATCPA indicated the 'traditional foods' and 'cereals and dairy product' patterns were mainly observed in the 41-50 age group with H-SES. "Fish and nut" and "smoked and pickled foods, and dessert" patterns were mainly observed among the $\geq 51 \mathrm{y}$ males in L-SES group. There is an absence of difference in four food consumption patterns among young females (aged $\leq 40$ years old) in the M-SES group.

\section{Discussion}

This retrospective study showed that the distributions of health-related behaviors and dietary habits varied by gender, age and SES among governmental employees in China. Males in the meddle-aged group (41-60) were more likely to smoke, use alcohol and have short sleep duration, but males in the 31-40 age group had the highest rate of leisure-time physical inactivity (59.6\%). Young females (age $\leq$ $30 \mathrm{y}$ ) were more likely to have leisure-time physical inactivity, but females aged $\geq 51$ y were more likely to have short sleep duration. Sedentary behavior, late sleeping, as well as all four risk eating behavior habits were more prevalent in youngest age group (age $\leq 30 \mathrm{y}$ ), regardless of gender. In addition, we found that people in the H-SES group were less likely to be current smoker and have physical inactivity, but were 
more likely to have late sleeping. We also identified four food consumption patterns, which varied by gender, age and SES.

We found gender and age differences in the occurrence of health-related behaviors. For instance, the rate of smoking and alcohol drinking were much lower in females than males, which may be explained by socio-cultural factors. The social gender role in culture consider it acceptable, appropriate, or even desirable to engage in certain behaviors such as smoking and drinking for males, but almost not for females [27-29]. In this study, a higher rate of smoking and alcohol drinking was found in middle-aged (41-60y) males than that in younger males ( $\leq 40 \mathrm{y})$. In recent years, the Chinese government has been gradually strengthening the policies against tobacco use, and the group intervention on smoking cessation based on social cognitive theory could be effective to reduce smoking[30, 31]. Male smokers in the high age group lacking health knowledgeable and ignoring the proper health behaviors, cannot sufficiently understand the need for preventive measures[32, 33], even reduce the stress of social isolation, economic hardship, prior trauma, and the loss of power and status by smoking [34]. In addition, we found young females and males had a high rate of leisure-time physical inactivity, late sleeping and sedentary behavior, which was consistent with previous research[35]. With the rapid socioeconomic development in China and changes in urbanization, work stress emerged in the urban population, especially among the working young population due to a rise in living costs, which may result in long working time and lacking leisure-time to participant in physical activity. Modern media use has also become intricately connected with our bedtime routine and sleep [36]. Additionally, individuals in the $\geq 51$ $y$ age group were more likely to have a high level of short sleep duration. These findings strongly suggest that planning of effective health promotion programs should target health-related behaviors that are modified by gender and age.

The association between SES and various health-related behaviors are multiple and complex[37]. Past studies have consistently shown SES as the strongest predictor of tobacco use [38-40]. In the current study, we found higher rate of smoking and leisure-time physical inactivity in the H-SES group than L-SES group, which were consistent with previous research $[41,42]$. Our study, for the first time, found higher rate of late sleeping in H-SES group than L-SES group among governmental employees in China. Tobacco control policies, leisure-time physical inactivity and late sleeping interventions in China should be increasingly focused on populations with low-SES in order to break the link between socioeconomic disadvantage and these unhealthy behaviors. Education, one of the components of SES, remained the strongest predictor of these unhealthy behaviors[38-40,42], suggesting future intervention programs to take targeted measures to reduce unhealthy behaviors, according to education attainment status. Although no significant differences in short sleep duration and sedentary behaviors were observed by SES in this study, we found much higher rate of short sleep duration and sedentary behaviors in our study population than the general population in southeast of China in other studies [41,43], drawing our attention to the impact of short sleep duration and sedentary behaviors on health among this special population [9]. 
We found differences in dietary habits including eating behavior habits and food consumption patterns by gender, age and SES. For eating behavior habits, both females and males in the younger age group ( $\leq$ 30 years) have the highest rate of these four unhealthy dietary habits. Younger individuals may get involved easily in unhealthy eating behaviors due to poor control awareness and health literacy $[19,20$, 44]. Although there were absent differences in four eating behaviors among three SES groups, combination of some other studies, SES remained an important factor to impact unhealthy eating behaviors [45-47].

We also explored food consumption patterns by socio-demographics using CATCPA analysis, which is the first study of its kind among governmental employees in China. We found the 'traditional foods' and 'cereals and dairy product' patterns were mainly observed in the 41-50 age group with H-SES. In China, traditional foods such as vegetables, fruits, meats and eggs were considered as healthy food pattern in line with Chinese traditions. Research has consistently shown that high intake of vegetables and fruits, whole grains, and eggs may decrease the risk of chronic diseases, even cancer[48, 49]. In addition, we found 'fish and nut' and 'smoked and pickled foods, and dessert' patterns were mainly observed among the $\geq 51$ y males in L-SES group. High intake of sugars, and pickled or smoked foods may increase such risk $[9,22,50,51]$, but fish consumption was associated with a reduced risk of all-cause mortality[52]. Available study has pointed out that males have a higher liking for sweets than females [53]. Younger age, low education, and low family income were associated with a poor health literacy status, which may result in a low nutrient food consumption[44]. The findings have implications for future intervention programs to take targeted measures to reduce unhealthy food consumption habits, according to specific sociodemographic characteristics.

To the best of our knowledge, this is the first study using a large sample from a representative urban governmental employee population. This is also the first study to use the CATPCA method to study health-related behaviors and dietary habits by socio-demographic characteristics such as gender, age and SES groups. However, some limitations should be considered when interpreting our results. First, many variables were self-reported and the findings may be subject to recall bias. Second, the study participants came from Hunan province and China, and the generalizability of the study findings may not be able to generalize to other parts of China despite its large sample size. Future multiprovince or multinational surveillance studies are needed to further test findings in our study. Third, the retrospective design of the current study may preclude any observation of behaviors and dietary habits changes over time. Future longitudinal studies may overcome such a limitation.

\section{Conclusions}

This study confirmed the various distribution of health-related behaviors and dietary habits by sociodemographic characteristics among governmental employees. Notably, this study found that middle-aged group (41-60 years) had the highest rates of smoking and alcohol drinking, and young-aged group ( $\leq 40$ years) with L-SES were more likely to have multiple unhealthy behaviors and dietary habits. We also identified four food consumption patterns, which varied by gender, age and SES. Our findings of 
the disparity distribution of health-related behaviors and dietary habits by specific-gender, age and SES among Chinses governmental employees have important policy implications for developing targeted health interventions to facilitate health-related behaviors and dietary habits in this population.

\section{Abbreviations}

SES: Socioeconomic status; L-SES: Low socioeconomic status; M-SES: Medium socioeconomic status; HSES: High socioeconomic status; CATPCA: Categorical principal components analysis.

\section{Declarations}

\section{Acknowledgements}

The authors thank the study participants for their contribution to the research and are thankful for the guidance of Xiangya School of Public Health, Central South University. Informed consent was obtained from all participants.

\section{Authors' contributions}

LL: study design, data analyses and interpretation, manuscript writing and revision. HJ, FYOY, DQ and YL: data acquisition, interpretation and manuscript revision. YY and DL: manuscript revision. SX: study conceptualisation, data acquisition and interpretation, and manuscript revision. All of authors approved the final content of this manuscript.

\section{Funding}

This research was supported by the Ministry of Science and Technology of China (Grant NO: 2016YFC0900802).

\section{Availability of data and materials}

The datasets used and/or analysed during the current study are available from the corresponding author on reasonable request.

\section{Ethics approval and consent to participate}

The study was approved by the Ethics Committee of Xiangya School of Public Health, Central South University (ethics approval number: XYGW-2016-10). Informed consent was obtained from all participants.

\section{Consent for publication}

Not applicable. 


\section{Competing interests}

The authors declare that they have no competing interests.

\section{Author details}

${ }^{1}$ Department of Social Medicine and Health Management, Xiangya School of Public Health, Central South University, Changsha 410078, Hunan, China. ${ }^{2}$ Hospital Evaluation Office, Xiangya Hospital, Central South University, Xiangya Road 87, Changsha, Hunan 410008 China. ${ }^{3}$ Division of Prevention and Community Research, Department of Psychiatry, Yale School of Medicine, 389 Whitney Avenue, New Haven, CT 06511 USA.

\section{References}

1. TZ Y. Health behavior theory and research. People's Medical publishing House. 2007.

2. Khaw KT, Wareham N, Bingham S, Welch A, Luben R, Day N. Combined impact of health behaviours and mortality in men and women: the EPIC-Norfolk prospective population study. PLoS Med. 2008;5:e12.

3. Mokdad AH, Marks JS, Stroup DF, Gerberding JL. Actual causes of death in the United States, 2000. JAMA. 2004;291:1238-45.

4. Fisher EB, Fitzgibbon ML, Glasgow RE, Haire-Joshu D, Hayman LL, Kaplan RM, et al. Behavior matters. Am J Prev Med. 2011;40:e15-30.

5. Alwan A, Maclean DR, Riley LM, d'Espaignet ET, Mathers CD, Stevens GA, et al. Monitoring and surveillance of chronic non-communicable diseases: progress and capacity in high-burden countries. Lancet. 2010;376:1861-8.

6. Danaei G, Ding EL, Mozaffarian D, Taylor B, Rehm J, Murray CJ, et al. The preventable causes of death in the United States: comparative risk assessment of dietary, lifestyle, and metabolic risk factors. PLoS Med. 2009;6:e1000058.

7. Lee $\mathrm{DH}, \mathrm{Ha} \mathrm{MH}, \mathrm{Kim}$ JR, Jacobs DR. Jr. Effects of smoking cessation on changes in blood pressure and incidence of hypertension: a 4-year follow-up study. Hypertension. 2001;37:194-8.

8. Dietary Habits. In. Preedy VR, Watson RR, editors. Handbook of Disease Burdens and Quality of Life Measures. New York: Springer New York; 2010. p. 4189.

9. Huang L, Chen L, Gui ZX, Liu S, Wei ZJ, Xu AM. Preventable lifestyle and eating habits associated with gastric adenocarcinoma: A case-control study. J Cancer. 2020;11:1231-9.

10. Bray F, Ferlay J, Soerjomataram I, Siegel RL, Torre LA, Jemal A. Global cancer statistics 2018: GLOBOCAN estimates of incidence and mortality worldwide for 36 cancers in 185 countries. Cancer J Clin. 2018;68:394-424.

11. Wang Z, Koh WP, Jin A, Wang R, Yuan JM. Composite protective lifestyle factors and risk of developing gastric adenocarcinoma: the Singapore Chinese Health Study. British journal of cancer. 
2017;116:679-87.

12. Koh HKSK. Promoting prevention through the affordable care act. N Engl J Med. 2010;363:8.

13. RS M. Global health governance and the challenge of chronic, non-communicable disease. J Law Med Ethics. 2010;38:8.

14. Kelishadi R, Ardalan G, Gheiratmand R, Majdzadeh R, Delavari A, Heshmat R, et al. Smoking behavior and its influencing factors in a national-representative sample of Iranian adolescents: CASPIAN study. Preventive medicine. 2006;42:423-6.

15. Petrovic D, de Mestral C, Bochud M, Bartley M, Kivimäki M, Vineis P, et al. The contribution of health behaviors to socioeconomic inequalities in health: A systematic review. Preventive medicine. 2018;113:15-31.

16. Heise L, Greene ME, Opper N, Stavropoulou M, Harper C, Nascimento M, et al. Gender inequality and restrictive gender norms: framing the challenges to health. The Lancet. 2019;393:2440-54.

17. Weber AM, Cislaghi. B, Meausoone. V, Mejía-Guevara AS. I, Loftus P, et al. Gender norms and health: insights from global survey data. The Lancet. 2019;393:14.

18. Edwards ES, Sackett SC. Psychosocial Variables Related to Why Women are Less Active than Men and Related Health Implications. Clinical medicine insights Women's health. 2016;9:47-56.

19. Tseng TS, Lin HY. Gender and age disparity in health-related behaviors and behavioral patterns based on a National Survey of Taiwan. Int J Behav Med. 2008;15:14-20.

20. Johansson L, Thelle DS, Solvoll K, Bjorneboe GE, Drevon CA. Healthy dietary habits in relation to social determinants and lifestyle factors. Br J Nutr. 1999;81:211-20.

21. Claassen MA, Klein O, Bratanova B, Claes N, Corneille O. A systematic review of psychosocial explanations for the relationship between socioeconomic status and body mass index. Appetite. 2019;132:208-21.

22. Hong $X, X u F$, Wang Z, Liang Y, Li J. Dietary patterns and the incidence of hyperglyacemia in China. Public Health Nutr. 2016;19:131-41.

23. Rozanska D, Waskiewicz A, Regulska-llow B, Kwasniewska M, Pajak A, Stepaniak U, et al. Relationship between the dietary glycemic load of the adult Polish population and sociodemographic and lifestyle factors - results of the WOBASZ II study. Adv Clin Exp Med. 2019;28:7.

24. Hosseinpoor AR, Bergen N, Kunst A, Harper S, Guthold R, Rekve D, et al. Socioeconomic inequalities in risk factors for non communicable diseases in low-income and middle-income countries: results from the World Health Survey. BMC Public Health. 2012;12:912.

25. Bonaccio M, Di Castelnuovo A, Bonanni A, Costanzo S, Persichillo M, Cerletti C, et al. Socioeconomic status and impact of the economic crisis on dietary habits in Italy: results from the INHES study. Journal of public health. 2018;40:703-12.

26. Zujko ME, Waskiewicz A, Drygas W, Cicha-Mikolajczyk A, Zujko K, Szczesniewska D, et al. Dietary Habits and Dietary Antioxidant Intake Are Related to Socioeconomic Status in Polish Adults: A Nationwide Study. Nutrients. 2020; 12. 
27. Schmitt DP, Long AE, McPhearson A, O'Brien K, Remmert B, Shah SH. Personality and gender differences in global perspective. International journal of psychology: Journal international de psychologie. 2017;52(Suppl 1):45-56.

28. Andrews JO, Heath J. Women and the global tobacco epidemic: nurses call to action. International nursing review, 2003; 50:215 - 28.

29. Tang H, Cai W, Wang H, Zhang Q, Qian L, Shell DF, et al. The association between cultural orientation and drinking behaviors among university students in Wuhan, China. PLoS One. 2013;8:e54796.

30. Zheng P, Zheng L, Guo F, Xiao X. [Evaluation of two-year follow-up of group intervention on smoking cessation based on social cognitive theory]. Wei Sheng Yan Jiu. 2008;37:53-6.

31. Hu TW, Zhang $X$, Zheng R. China has raised the tax on cigarettes: what's next? Tobacco control. 2016;25:609-11.

32. He Z, Cheng Z, Shao T, Liu C, Shao P, Bishwajit G, et al. Factors Influencing Health Knowledge and Behaviors among the Elderly in Rural China. Int J Environ Res Public Health. 2016; 13.

33. Maguire CP, Ryan J, Kelly A, O'Neill D, Coakley D, Walsh JB. Do patient age and medical condition influence medical advice to stop smoking? Age and ageing, 2000; 29:264-6.

34. Burgess DJ, Mock J, Schillo BA, Saul JE, Phan T, Chhith Y, et al. Culture, acculturation and smoking use in Hmong, Khmer, Laotians, and Vietnamese communities in Minnesota. Bmc Public Health. 2014; 14.

35. Hobbs M, Duncan MJ, Collins P, McKenna J, Schoeppe S, Rebar AL, et al. Clusters of health behaviours in Queensland adults are associated with different socio-demographic characteristics. Journal of public health. 2019;41:268-77.

36. Exelmans L, Van den Bulck J. Bedtime mobile phone use and sleep in adults. Soc Sci Med. 2016;148:93-101.

37. World Health Organization. FRAMEWORK FOR ACTION ON THE SOCIAL DETERMINANTS OF HEALTH. World Health Organization. Geneva;2010.

38. Samuel P, Antonisamy B, Raghupathy P, Richard J, Fall CH. Socio-economic status and cardiovascular risk factors in rural and urban areas of Vellore, Tamilnadu, South India. Int $\mathrm{J}$ Epidemiol. 2012;41:1315-27.

39. Hosseinpoor AR, Parker LA, Tursan d'Espaignet E, Chatterji S. Socioeconomic inequality in smoking in low-income and middle-income countries: results from the World Health Survey. PLoS One. 2012;7:e42843.

40. Sanderson E, Davey Smith G, Bowden J, Munafo MR. Mendelian randomisation analysis of the effect of educational attainment and cognitive ability on smoking behaviour. Nat Commun. 2019;10:2949.

41. Mingling Chen YW, Hiroto Narimatsu X, Li C, Wang J, Luo G, Zhao Z, Chen. Wanghong Xu. Socioeconomic Status and Physical Activity in Chinese Adults: A Report from a Community-Based Survey in Jiaxing, China. PLoS One. 2015; e0132918. 
42. Wang Q, Shen JJ, Sotero M, Li CA, Hou Z. Income, occupation and education: Are they related to smoking behaviors in China? PLoS One. 2018;13:e0192571.

43. Wu HB, Wang H, Hu RY, Zhong JM, Qian YJ, Wang CM, et al. The association between sleep duration, snoring and prevalent type 2 diabetes mellitus with regard to gender and menopausal status: the CKB study in Zhejiang rural area, China. Acta diabetologica. 2017;54:81-90.

44. Wang X, Guo H, Wang L, Li X, Huang M, Liu Z, et al. Investigation of residents' health literacy status and its risk factors in Jiangsu Province of China. Asia-Pacific journal of public health. 2015;27:Np2764-72.

45. Allen L, Williams J, Townsend N, Mikkelsen B, Roberts N, Foster C, et al. Socioeconomic status and non-communicable disease behavioural risk factors in low-income and lower-middle-income countries: a systematic review. The Lancet Global Health. 2017;5:e277-e89.

46. Caldwell AE, Sayer RD. Evolutionary considerations on social status, eating behavior, and obesity. Appetite. 2019;132:238-48.

47. Keski-Rahkonen A, Kaprio J, Rissanen A, Virkkunen M, Rose RJ. Breakfast skipping and healthcompromising behaviors in adolescents and adults. Eur J Clin Nutr. 2003;57:842-53.

48. Guasch-Ferré M, Liu X, Malik VS, Sun Q, Willett WC, Manson JE, et al. Nut Consumption and Risk of Cardiovascular Disease. J Am Coll Cardiol. 2017;70:2519-32.

49. Tørris C, Småstuen MC, Molin M. Nutrients in Fish and Possible Associations with Cardiovascular Disease Risk Factors in Metabolic Syndrome. Nutrients. 2018; 10.

50. Villegas R, Yang G, Gao YT, Cai H, Li H, Zheng W, et al. Dietary patterns are associated with lower incidence of type 2 diabetes in middle-aged women: the Shanghai Women's Health Study. Int $\mathrm{J}$ Epidemiol. 2010;39:889-99.

51. Rouhani MH, Agh F, Azadbakht L. Pickle Consumption is Associated with Body Mass Index and Blood Pressure among Iranian Female College Students: a Cross-Sectional Study. Clinical nutrition research. 2018;7:256-65.

52. Zhao LG, Sun JW, Yang Y, Ma X, Wang YY, Xiang YB. Fish consumption and all-cause mortality: a meta-analysis of cohort studies. Eur J Clin Nutr. 2016;70:155-61.

53. Lampure A, Schlich P, Deglaire A, Castetbon K, Peneau S, Hercberg S, et al. Sociodemographic, psychological, and lifestyle characteristics are associated with a liking for salty and sweet tastes in French adults. J Nutr. 2015;145:587-94.

\section{Tables}

Table 1. Discretization criteria used in the Principal Components Analysis of Categorical Data. 


\begin{tabular}{|c|c|c|c|}
\hline Variable & Property & Criteria for classification & $\begin{array}{l}\text { Assumable } \\
\text { value }\end{array}$ \\
\hline Gender & Dichotomous & Male; female & 1,2 \\
\hline Age & Ordinal & $\leq 29 \square 30-40 ; 41-64 ; \geq 65$ & $1,2,3,4$ \\
\hline SES & Ordinal & SES score:<=10; 11-16; 17-42 & $1,2,3$ \\
\hline Rice consumption habit & Dichotomous & $\begin{array}{l}\text { less than } 3 \text { days/week; } \\
\text { more than } 3 \text { days/week }\end{array}$ & 1,2 \\
\hline $\begin{array}{l}\text { Vegetables consumption } \\
\text { habit }\end{array}$ & Dichotomous & $\begin{array}{l}\text { less than } 3 \text { days/week; } \\
\text { more than } 3 \text { days/week }\end{array}$ & 1,2 \\
\hline $\begin{array}{l}\text { Wheat consumption } \\
\text { habit }\end{array}$ & Dichotomous & $\begin{array}{l}\text { less than } 3 \text { days/week; } \\
\text { more than } 3 \text { days/week }\end{array}$ & 1,2 \\
\hline Grain consumption habit & Dichotomous & $\begin{array}{l}\text { less than } 3 \text { days/week; } \\
\text { more than } 3 \text { davs/week }\end{array}$ & 1,2 \\
\hline $\begin{array}{l}\text { Fish consumption } \\
\text { habit }\end{array}$ & Dichotomous & $\begin{array}{l}\text { less than } 3 \text { days/week; } \\
\text { more than } 3 \text { days/week }\end{array}$ & 1,2 \\
\hline $\begin{array}{l}\text { Livestock meat } \\
\text { consumption habit }\end{array}$ & Dichotomous & $\begin{array}{l}\text { less than } 3 \text { days/week; } \\
\text { more than } 3 \text { days/week }\end{array}$ & 1,2 \\
\hline $\begin{array}{l}\text { Poultry meat } \\
\text { consumption habit }\end{array}$ & Dichotomous & $\begin{array}{l}\text { less than } 3 \text { days/week; } \\
\text { more than } 3 \text { days/week }\end{array}$ & 1,2 \\
\hline Soybean and products & Dichotomous & $\begin{array}{l}\text { less than } 3 \text { days/week; } \\
\text { more than } 3 \text { days/week }\end{array}$ & 1,2 \\
\hline Fruits consumption habit & Dichotomous & $\begin{array}{l}\text { less than } 3 \text { days/week; } \\
\text { more than } 3 \text { days/week }\end{array}$ & 1,2 \\
\hline Egg consumption habit & Dichotomous & $\begin{array}{l}\text { less than } 3 \text { days/week; } \\
\text { more than } 3 \text { days/week }\end{array}$ & 1,2 \\
\hline $\begin{array}{l}\text { Dairy products } \\
\text { consumption habit }\end{array}$ & Dichotomous & $\begin{array}{l}\text { less than } 3 \text { days/week; } \\
\text { more than } 3 \text { days/week }\end{array}$ & 1,2 \\
\hline Nut consumption habit & Dichotomous & $\begin{array}{l}\text { less than } 3 \text { days/week; } \\
\text { more than } 3 \text { days/week }\end{array}$ & 1,2 \\
\hline $\begin{array}{l}\text { Dessert consumption } \\
\text { habit }\end{array}$ & Dichotomous & $\begin{array}{l}\text { less than } 3 \text { days/week; } \\
\text { more than } 3 \text { days/week }\end{array}$ & 1,2 \\
\hline
\end{tabular}

Table 2. Characteristics of study participants. 


\begin{tabular}{|c|c|c|}
\hline Variable & Frequency & Weighted percentage \\
\hline \multicolumn{3}{|l|}{ Gender } \\
\hline Male & 2023 & 40.2 \\
\hline Female & 3006 & 59.8 \\
\hline \multicolumn{3}{|l|}{ Age } \\
\hline$\leq 30 y$ & 981 & 19.6 \\
\hline $31-40 y$ & 2017 & 40.1 \\
\hline $41-50 y$ & 1245 & 24.8 \\
\hline$>=51 \mathrm{y}$ & 786 & 15.6 \\
\hline \multicolumn{3}{|l|}{ Marital status } \\
\hline Married/cohabited & 4265 & 84.8 \\
\hline Unmarried & 619 & 12.3 \\
\hline Divorced/widowed & 145 & 2.9 \\
\hline \multicolumn{3}{|l|}{ Education } \\
\hline 1.Elementary school or below & 8 & 0.2 \\
\hline 2.Middle school & 40 & 0.8 \\
\hline 3.Vocational Technical School & 75 & 1.5 \\
\hline 4.Senior school & 149 & 3.0 \\
\hline 5.Undergraduate and college & 2677 & 53.2 \\
\hline 6.Postgraduate and above & 2080 & 41.4 \\
\hline \multicolumn{3}{|l|}{ Family income (CNY) } \\
\hline $1 .<50,000$ & 525 & 10.4 \\
\hline $2.50,000-100,000$ & 1186 & 23.6 \\
\hline $3.110,000-200,000$ & 1893 & 37.6 \\
\hline $4.210,000-300,000$ & 944 & 18.8 \\
\hline $5.310,000-500,000$ & 378 & 7.5 \\
\hline $6.510,000-1000,000$ & 83 & 1.7 \\
\hline 7.>1000,000 & 20 & 0.4 \\
\hline \multicolumn{3}{|l|}{$\mathrm{SES}^{*}$} \\
\hline Low & 1777 & 35.3 \\
\hline Medium & 1838 & 36.6 \\
\hline High & 1414 & 28.1 \\
\hline Smoking (current) & 601 & 12.0 \\
\hline Drinking (current) & 338 & 6.7 \\
\hline Leisure-time physical inactivity ${ }^{a}$ & 2756 & 54.8 \\
\hline Sedentary behavior $\mathrm{b}$ & 3761 & 74.8 \\
\hline Late sleeping ${ }^{\mathrm{c}}$ & 836 & 16.6 \\
\hline Short sleep duration ${ }^{d}$ & 1723 & 34.4 \\
\hline Irregular meals habit ${ }^{\mathrm{e}}$ & 1926 & 38.3 \\
\hline Eating midnight snack & 98 & 2.0 \\
\hline Eating gluttony habit & 242 & 4.8 \\
\hline Salty taste habit & 1404 & 26.1 \\
\hline
\end{tabular}

${ }^{*}$ SES: socioeconomic status was calculated as education multiplied by family income. 
${ }^{a}$ Leisure-time physical inactivity was defined as $30 \mathrm{~min} /$ day of physical activity at a frequency of once per week or less.

b Sedentary behavior was defined as the time spent sitting (such as watching TV, surfing the Internet, etc.) more than 2 hours/day in addition to work and study.

${ }^{\mathrm{C}}$ Late sleeping was defined as the time to fall asleep after midnight.

d Short sleep duration was defined as sleep time less than 7 hours per night.

${ }^{\mathrm{e}}$ Irregular meals habit was defined as not eating three meals on time per day.

Table 3. Distribution of health-related behaviors and eating behavior habits by age and gender. 


\begin{tabular}{|c|c|c|c|c|c|c|c|c|c|}
\hline \multirow[t]{4}{*}{ Characteristics } & \multirow[t]{4}{*}{$\begin{array}{l}\text { Gender } \\
\mathrm{f}\end{array}$} & \multirow{2}{*}{\multicolumn{2}{|c|}{$\begin{array}{l}\text { Age } \leq 30 \\
M(n= \\
282)\end{array}$}} & \multicolumn{2}{|c|}{$\begin{array}{l}\text { Age 31- } \\
40\end{array}$} & \multicolumn{2}{|c|}{$\begin{array}{l}\text { Age 41- } \\
50\end{array}$} & \multicolumn{2}{|c|}{ Age $\geq 51$} \\
\hline & & & & \multicolumn{2}{|c|}{$\begin{array}{l}M(n= \\
705)\end{array}$} & \multicolumn{2}{|c|}{$\begin{array}{l}\mathrm{M}(n= \\
577)\end{array}$} & \multicolumn{2}{|c|}{$\begin{array}{l}M(n= \\
459)\end{array}$} \\
\hline & & \multicolumn{2}{|c|}{$\begin{array}{l}F(n= \\
699)\end{array}$} & \multicolumn{2}{|c|}{$\begin{array}{l}\mathrm{F}(n= \\
1312)\end{array}$} & \multicolumn{2}{|c|}{$\begin{array}{l}\mathrm{F}(n= \\
668)\end{array}$} & \multicolumn{2}{|c|}{$\begin{array}{l}\mathrm{F}(\mathrm{n}= \\
327)\end{array}$} \\
\hline & & $n$ & $\%$ & $n$ & $\%$ & $n$ & $\%$ & $n$ & $\%$ \\
\hline \multicolumn{10}{|l|}{ Health-related } \\
\hline \multirow{2}{*}{ Smoking (current) } & M & 55 & 19.5 & 176 & 25.0 & 191 & 33.1 & 166 & 36.2 \\
\hline & $\mathrm{F}$ & 2 & 0.3 & 2 & 0.2 & 7 & 1.0 & 1 & 0.3 \\
\hline \multirow{2}{*}{$\begin{array}{l}\text { Alcohol drinking } \\
\text { (current) }\end{array}$} & M & 18 & 6.4 & 81 & 11.5 & 115 & 19.9 & 118 & 25.7 \\
\hline & $\mathrm{F}$ & 0 & 0.0 & 2 & 0.2 & 3 & 0.4 & 1 & 0.3 \\
\hline \multirow{2}{*}{$\begin{array}{l}\text { Leisure-time physical } \\
\text { inactivity }^{\text {a }}\end{array}$} & $\mathrm{M}$ & 149 & 52.8 & 420 & 59.6 & 262 & 45.4 & 157 & 34.2 \\
\hline & $\mathrm{F}$ & 485 & 69.4 & 898 & 68.4 & 287 & 43.0 & 98 & 30.0 \\
\hline \multirow{2}{*}{ Sedentary behavior $\mathrm{b}$} & $\mathrm{M}$ & 227 & 80.4 & 521 & 73.9 & 442 & 76.6 & 351 & 76.5 \\
\hline & $\mathrm{F}$ & 571 & 81.7 & 921 & 70.2 & 491 & 73.5 & 237 & 72.5 \\
\hline \multirow{2}{*}{ Late sleeping ${ }^{\mathrm{c}}$} & $\mathrm{M}$ & 85 & 30.1 & 136 & 19.3 & 79 & 13.7 & 64 & 13.9 \\
\hline & $\mathrm{F}$ & 145 & 20.7 & 192 & 14.6 & 99 & 14.8 & 36 & 11.0 \\
\hline \multirow{2}{*}{ Short sleep duration ${ }^{d}$} & $\mathrm{M}$ & 74 & 26.2 & 230 & 32.6 & 197 & 34.1 & 179 & 39.0 \\
\hline & $\mathrm{F}$ & 195 & 27.9 & 441 & 33.6 & 260 & 38.9 & 147 & 45.4 \\
\hline \multicolumn{10}{|l|}{ Eating behavior habits } \\
\hline \multirow[t]{2}{*}{ Irregular meals habit $\mathrm{e}$} & M & 142 & 50.4 & 283 & 40.1 & 153 & 26.5 & 99 & 21.6 \\
\hline & $\mathrm{F}$ & 427 & 61.1 & 546 & 41.6 & 196 & 29.3 & 80 & 24.5 \\
\hline \multirow[t]{2}{*}{ Eating midnight snack } & $\mathrm{M}$ & 10 & 3.5 & 17 & 2.4 & 3 & 0.5 & 5 & 1.1 \\
\hline & $\mathrm{F}$ & 27 & 3.9 & 29 & 2.2 & 5 & 0.7 & 2 & 0.5 \\
\hline \multirow[t]{2}{*}{ Eating gluttony habit } & $\mathrm{M}$ & 29 & 10.3 & 37 & 5.2 & 25 & 4.3 & 22 & 4.8 \\
\hline & $\mathrm{F}$ & 49 & 7.0 & 58 & 4.4 & 12 & 1.8 & 10 & 3.1 \\
\hline \multirow[t]{2}{*}{ Salty taste habit } & $\mathrm{M}$ & 101 & 35.8 & 245 & 34.8 & 177 & 30.8 & 147 & 32.0 \\
\hline & $\mathrm{F}$ & 179 & 25.6 & 283 & 21.6 & 123 & 18.4 & 59 & 18.0 \\
\hline
\end{tabular}

${ }^{a}$ Leisure-time physical inactivity was defined as $30 \mathrm{~min} /$ day of physical activity at a frequency of once per week or less.

b Sedentary behavior was defined as the time spent sitting (such as watching TV, surfing the Internet, etc.) more than 2 hours/day in addition to work and study.

${ }^{\mathrm{c}}$ Late sleeping was defined as the time to fall asleep over 24 o'clock.

d Short sleep duration was defined as sleep time less than 7 hours per night.

${ }^{\mathrm{e}}$ Irregular meals habit was defined as being not eat three meals on time per day.

${ }^{\mathrm{f}} \mathrm{M}$ : male; F: female. 
Table 4. Distribution of health-related behaviors and eating behavior habits by socioeconomic status.

\begin{tabular}{|c|c|c|c|c|c|c|c|}
\hline \multirow[t]{3}{*}{ Characteristics } & \multirow{2}{*}{\multicolumn{2}{|c|}{$\begin{array}{c}\text { Low } \\
\mathrm{N}=1605\end{array}$}} & \multirow{2}{*}{\multicolumn{2}{|c|}{$\begin{array}{c}\text { Intermediate } \\
\mathrm{N}=1577\end{array}$}} & \multirow{2}{*}{\multicolumn{2}{|c|}{$\begin{array}{c}\text { High } \\
\mathrm{N}=2250\end{array}$}} & \multirow[t]{3}{*}{$\begin{array}{l}\text { p- } \\
\text { value }\end{array}$} \\
\hline & & & & & & & \\
\hline & $\mathrm{n}$ & $\%$ & $\mathrm{n}$ & $\%$ & $\mathrm{n}$ & $\%$ & \\
\hline \multicolumn{8}{|l|}{ Health-related behaviors } \\
\hline Smoking (current) & 244 & 13.7 & 196 & 10.7 & 161 & 11.4 & 0.006 \\
\hline Drinking alcohol(current) & 117 & 6.6 & 118 & 6.4 & 103 & 7.3 & 0.739 \\
\hline $\begin{array}{l}\text { Leisure-time physical } \\
\text { inactivity a }\end{array}$ & 966 & 54.4 & 1056 & 57.5 & 734 & 51.9 & 0.028 \\
\hline Sedentary behavior $b$ & 1324 & 74.5 & 1374 & 74.8 & 1063 & 75.2 & 0.234 \\
\hline Late sleeping ${ }^{c}$ & 270 & 15.2 & 304 & 16.5 & 262 & 18.5 & \multirow{2}{*}{$\begin{array}{l}< \\
0.001 \\
0.290\end{array}$} \\
\hline $\begin{array}{l}\text { Short sleep duration }{ }^{d} \\
\text { Eating behavior habit }\end{array}$ & 623 & 35.1 & 634 & 34.5 & 466 & 33.0 & \\
\hline Irregular meals habit $\mathrm{e}$ & 715 & 40.2 & 717 & 39.0 & 494 & 34.9 & 0.128 \\
\hline Eating midnight snack & 34 & 1.9 & 40 & 2.2 & 24 & 1.7 & 0.934 \\
\hline Eating gluttony habit & 85 & 4.8 & 98 & 5.3 & 59 & 4.2 & 0.803 \\
\hline Salty taste habit & 464 & 26.1 & 472 & 25.7 & 378 & 26.7 & 0.722 \\
\hline
\end{tabular}

${ }^{a}$ Leisure-time physical inactivity was defined as 30 min/day of physical activity at a frequency of once per week or less.

b Sedentary behavior was defined as the time spent sitting (such as watching TV, surfing the Internet, etc.) more than 2 hours/day in addition to work and study.

${ }^{\mathrm{C}}$ Late sleeping was defined as the time to fall asleep over 24 o'clock.

d Short sleep duration was defined as sleep time less than 7 hours per night.

e Irregular meals habit was defined as being not eat three meals on time per day.

\section{Figures}




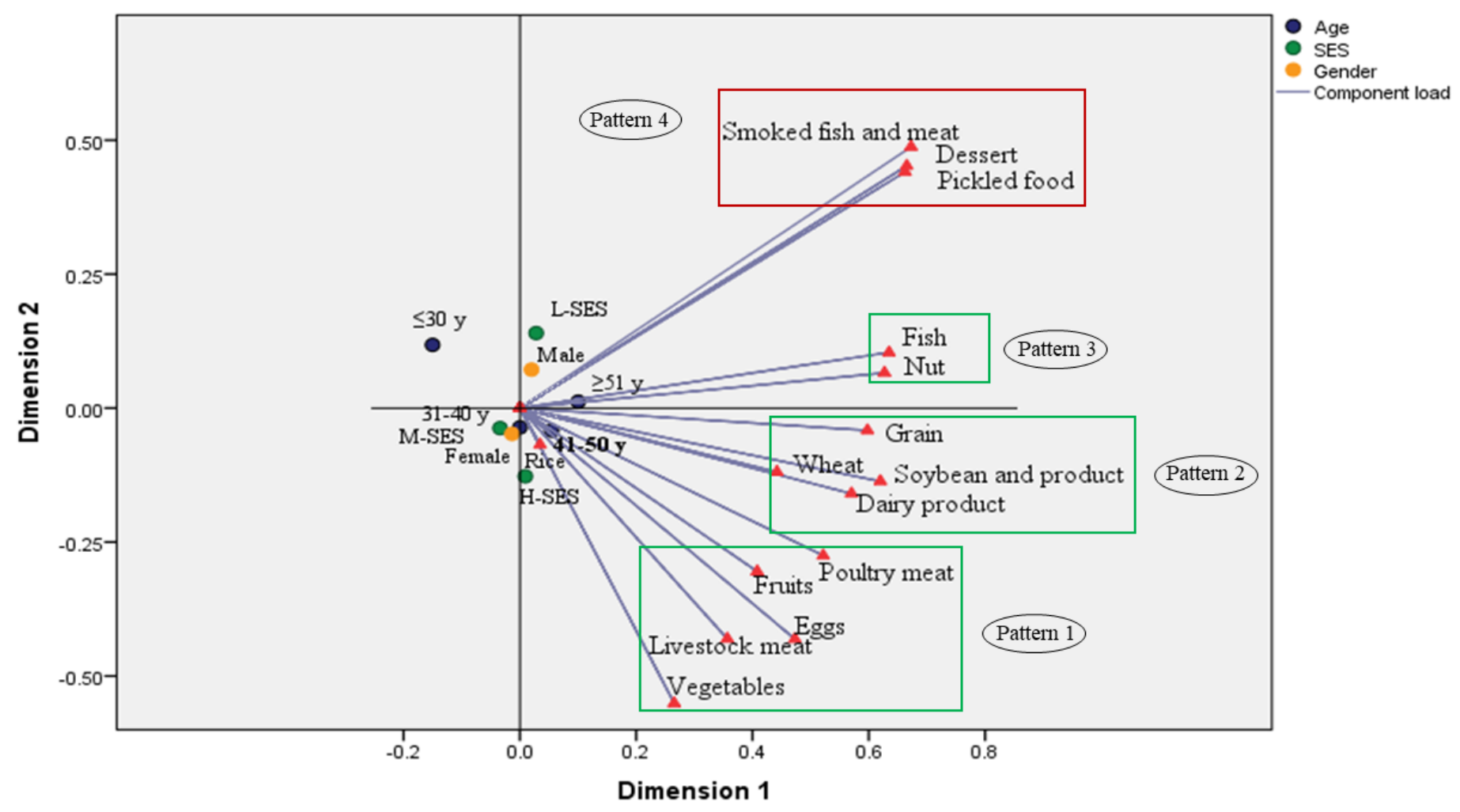

\section{Figure 1}

Principal Components Analysis of Categorical Data (Cronbach's alpha=0.887; eigenvalue=5.812). Variables in association: Pattern 1 named 'traditional foods' pattern was characterized by more consumption of vegetables, livestock and poultry meat, fruits and eggs. Pattern 2 named 'cereals and dairy product' pattern was characterized by more consumption of grain, wheat, soybean and products, and dairy product. Pattern 3 named 'fish and nut' pattern was characterized by more consumption of fish and nut. Pattern 4 named 'smoked and pickled foods, and dessert' pattern was characterized by more consumption of smoked fish or meat, pickle food and dessert; SES, socioeconomic status; L-SES: lowsocioeconomic status; M-SES, medium- socioeconomic status; H-SES, high- socioeconomic status. 